\title{
Kenyamanan Pencapaian Pengguna Bangunan Rumah Sakit Multi Massa terhadap Desain Sirkulasi sebagai Penghubung Antarfungsi Bangunan
}

\author{
Theresia Pynkyawati, Panji Meilan, Alfonzo Dianro Rafles, Bayu Mirza Dwi Putro \\ Program Studi Arsitektur, Fakultas Arsitektur dan Desain \\ Institut Teknologi Nasional Bandung \\ Email: thres@itenas.ac.id
}

\begin{abstract}
ABSTRAK
Rumah sakit merupakan sebuah sarana penunjang bagi masyarakat dalam memenuhi kebutuhan jasmani ketika dalam kondisi sakit ataupun saat mengalami kecelakaan darurat. Sarana maupun prasarana yang tersedia pada rumah sakit diharapkan dapat memberikan kenyamanan terhadap pasien, maupun staff tenaga medis dan non medis. Sarana sirkulasi menjadi sebuah penghubung kegiatan di dalam sebuah bangunan. Pola sirkulasi yang baik akan mempermudah pengguna bangunan dalam beraktifitas. Desain rancangan Rumah Sakit Dustira menerapkan konsep bangunan dengan tatanan multi massa. Dampak dari konsep ini menyebabkan setiap bangunan pada kawasan memiliki jarak pencapaian yang berbeda. Adapun maksud dari penelitian ini bertujuan untuk mengukur tingkat kenyamanan pencapaian pada pengguna di kawasan rumah sakit. Metode analisa dilakukan secara kualitatif terhadap kenyamanan sirkulasi yang diuraikan secara deskriptif dan mengacu pada teori kenyamanan pencapaian, zoning pada rumah sakit, dan teori konsep tatanan massa. Hasil analisis menunjukan bahwa kenyamanan pencapaian pada setiap kebutuhan medis cukup nyaman, dengan pola sirkulasi yang teratur dan zoning yang jelas ditambah adanya signage disetiap node dapat membantu pengunjung atau pasien dalam menemukan gedung medis yang dituju.
\end{abstract}

Kata kunci: Rumah Sakit, multi massa, kenyamanan pencapaian, sirkulasi, pengguna bangunnan

\begin{abstract}
The hospital is a supporting facility for the community in meeting physical needs when they are sick or when experiencing an emergency accident. Facilities and infrastructure available at the hospital are expected to provide comfort to patients, as well as medical and non-medical staff. The means of circulation become a hub of activity in a building. A good circulation pattern will facilitate building users in their activities. The design design of the Dustira Hospital applies the concept of building with a multi-mass order. The impact of this concept causes each building in the region to have different achievement distances. The purpose of this study aims to measure the level of comfort of achievement for users in the hospital area. The method of analysis is carried out qualitatively on the convenience of circulation which is described descriptively and refers to the theory of comfort of achievement, zoning in hospitals, and the theory of the concept of mass order. The results of the analysis show that the comfort of achievement in each medical need is quite comfortable, with regular circulation patterns and clear zoning plus the presence of signage in each node can help visitors or patients find the intended medical building.
\end{abstract}

Keywords: Hospital, multi mass, comfort achievement, circulation, building users 


\section{PENDAHULUAN}

Rumah sakit merupakan layanan medis bagi seluruh rakyat. Penting bagi kota-kota besar maupun kota kecil memiliki layanan kesehatan umum bagi masyarakatnya. Layanan medis menjadi sarana yang penting bagi masyarakat dalam mengobati hingga mencegah penyakit yang kemungkinan di derita. Pengguna dari layanan medis ini berasal dari segala kalangan. Rumah sakit banyak jenisnya, yang dapat dilihat berdasarkan lokasi, situasi, dan berdasarkan spesialistik pelayanannya. Rumah sakit terbagi pula menjadi beberapa kelas, dilihat berdasarkan dari jumlah fasilitas dan layanan yang tersedia.

Sirkulasi pada sebuah bangunan dapat diartikan sebagai pembuluh darah pada manusia. Jika terjadi gangguan pada penyaluran di pembuluh darah tentunya akan mengganggu kesehatan pada tubuh kita. Sama halnya dengan sirkulasi, jika sirkulasi pada bangunan tidak terencana maka kegiatan pada bangunan tersebut akan terasa tidak nyaman. Sirkulasi yang baik pada bangunan rumah sakit menjadi faktor penting dilihat dari banyak dan padatnya pasien yang datang untuk mengatasi masalah kesehatannya.

Rumah Sakit Dustira merupakan sebuah fasilitas layanan medis yang berdiri pada tahun 1887 di masa penjajahan Hindia-Belanda sebagai rumah sakit militer. Rumah Sakit Dustira tetap berdiri hingga saat ini sebagai layanan medis yang melayanai TNI dan masyarakat umum. Hingga kini Rumah Sakit Dustira terus berkembang dengan adanya bangunan baru guna mencukupi fasilitas medis bagi pelayanan masyarakat. Pengembangan ini di wujudkan dengan cara penambahan massa-massa bangunan baru yang berdampak pada tatanan fungsi bangunan rumah sakit menjadi multi massa, dengan memiliki perbedaan fungsi pelayanan medis berdasarkan zona fungsi rumah sakit.

Pada kawasan Rumah Sakit Dustira fungsi medis terbagi menjadi beberapa massa, dan setiap massa memiliki fungsi medis yang berbeda, sehingga mengakibatkan pada satu kawasan rumah sakit memiliki jumlah massa yang cukup banyak. Banyaknya massa akan berpengaruh pada sistem sirkulasi yang menjadi sarana transportasi penghubung kegiatan di rumah sakit. Penerapan desain sirkulasi ini perlu diperhatikan dari segi jarak, besaran ruang gerak, hingga ke jelasan orientasi pencapaian yang mempengaruhi kenyamanan pengguna dalam bersikulasi di kawasan Rumah Sakit Dustira. Untuk itu desain sirkulasi menjadi hal penting untuk direncanakan dalam sebuah bangunan terutama bangunan pelayanan bagi kesehatan masyarakat bersifat preventif, kuratif dan rehabilitatif.

\subsection{Rumah Sakit}

Berdasarkan Permenkes No 34 tahun 2016, rumah sakit adalah institusi pelayanan kesehatan yang menyelenggarakan pelayanan kesehatan perorangan secara penuh dan lengkap yang menyediakan pelayanan rawat inap, rawat jalan, dan gawat darurat [1]. Adapun klasifikasi rumah sakit dapat dilihat berdasarkan jumlah jenis pelayanan dan jumlah kamar yang tersedia untuk perawatan pasien seperti pada Tabel 1.

Tabel 1. Klasifikasi rumah sakit berdasarkan jenis pelayanan

\begin{tabular}{|c|c|c|c|c|c|}
\hline \multirow{2}{*}{ Fasilitas } & \multicolumn{4}{|c|}{ Kelas } & \multirow{2}{*}{ Keterangan } \\
\hline & $\mathbf{A}$ & $\mathbf{B}$ & $\mathrm{C}$ & D & \\
\hline $\begin{array}{c}\text { Kamar Tidur } \\
\text { Pasien }\end{array}$ & 400 & 200 & 100 & 50 & \multirow{2}{*}{$\begin{array}{l}\text { - Spesialistik adalah suatu } \\
\text { keahlian ilmu kedokteran } \\
\text { dalam } 1 \text { bidang kesehatan luas } \\
\text { - Sub Spesialistik adalah suatu } \\
\text { keahlian ilmu kedokteran } \\
\text { dalam } 1 \text { bidang kesehatan yang } \\
\text { lebih spesifik }\end{array}$} \\
\hline $\begin{array}{c}\text { Fasilitas } \\
\text { Kemampuan } \\
\text { Pelayanan }\end{array}$ & $\begin{array}{c}\text { Spesialistik } \\
\text { dan Sub } \\
\text { Spesialistik } \\
\text { luas }\end{array}$ & $\begin{array}{c}\text { Spesialistik } \\
11 \text { jenis }\end{array}$ & $\begin{array}{c}\text { Spesialistik } \\
4 \text { jenis }\end{array}$ & $\begin{array}{c}\text { Spesialistik } 2 \\
\text { jenis }\end{array}$ & \\
\hline
\end{tabular}

Sumber: Peraturan Mentri Kesehatan No 34 tahun 2016 [1] 


\subsection{Tatanan Massa}

Tatanan massa adalah perletakan massa bangunan majemuk pada suatu site, yang ditata berdasarkan zona dan tuntutan lain yang menunjang tata letak massa bangunan ini di samping berdasarkan zonasi, juga harus dibuat berdasarkan alur sirkulasi yang saling terkait. Massa sebagai elemen site dapat tersusun dari massa berbentuk bangunan dan vegetasi; kedua - duanya baik secara individual maupun kelompok menjadi unsur pembentuk ruang out door [2].

\subsection{Zonning Ruang}

Rumah sakit terbagi menjadi beberapa zona, yaitu; zona OPD, IPD, CMU (Central Medical Unit), Administrasi, dan Servis. Dalam membagi ke 5 (lima) zona tersebut unit perawatan (zona IPD) menjadi fungsi central pada sebuah bangunan rumah sakit. Unit perawatan merupakan unit dimana pasien mendapatkan perawatan lanjut berdasarkan saran dari dokter. Ketika pasien dalam kondisi darurat unit perawatan harus mudah terhubung dengan ruang lainnya, sehingga ruang pendukung di sekelilingnya mudah diakses dari unit perawatan [3].

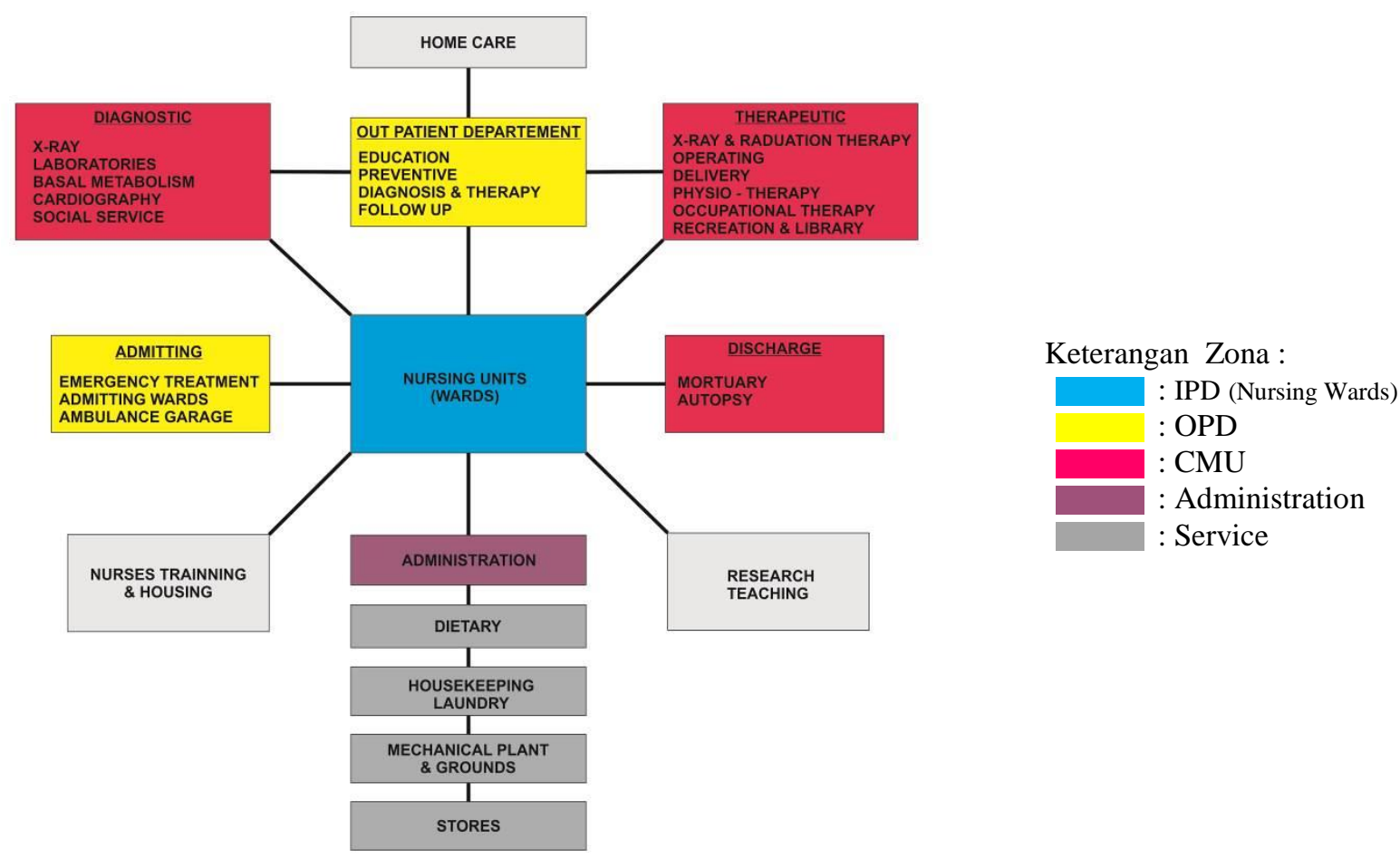

Gambar 1. Zoning dan konektivitas ruang pada rumah sakit

Sumber: Rosenfield, Isadore. 1956. [3]

\subsection{Sistem Sirkulasi pada Bangunan}

Sirkulasi dapat diartikan sebagai jalur aktifitas manusia ataupun kendaraan pada sebuah bangunan. Sistem sirkulasi adalah prasarana penghubung vital yang menghubungkan berbagai kegiatan dan penggunaan suatu lahan di atas suatu area dan di dalam bangunan yang mempertimbangkan aspek fungsional, ekonomis, dan kenyamanan [4].

Pada dasarnya sirkulasi dapat dibagi 3 berdasarkan fungsinya, yaitu:

a. Sirkulasi Manusia

b. Sirkulasi Kendaraan

c. Sirkulasi Barang 
Sistem sirkulasi memiliki dua tujuan, di antaranya yakni:

a. Mempunyai maksud tertentu dan berorientasi ke tempat tujuan, lebih bersifat langsung. Pemakai mengharapkan bahwa perjalanan dalam sistem ini akan lebih singkat dan cepat dengan jarak seminimal mungkin.

b. Bersifat rekreasi dengan waktu tidak menjadi batasan. Kenyamanan dan kenikmatan lebih diutamakan.

\subsection{Unsur-Unsur Sirkulasi}

Ada beberapa unsur-unsur sirkulasi di dalam bangunan maupun di luar bangunan [5], unsur-unsur tersebut dapat dilihat pada Tabel 2.

\section{Tabel 2. Unsur-unsur sirkulasi}

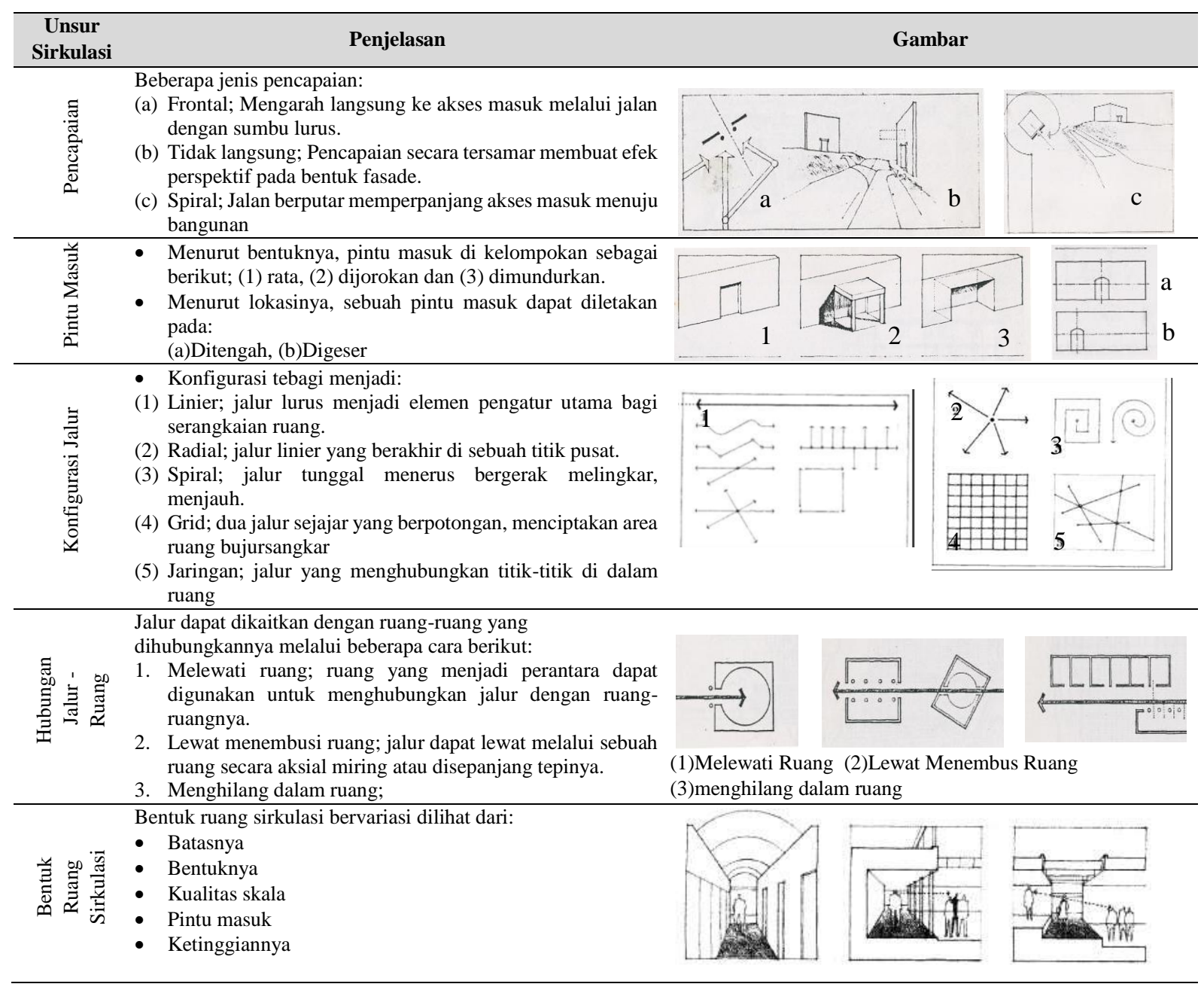

Sumber: Ching, Francis D.K. 2009. Bentuk, Ruang, dan Tatanan [5]

\subsection{Dimensi Ruang}

Dimensi Ruang merupakan sebuah ukuran yang diterapkan pada sebuah bangunan baik panjang, lebar maupun tinggi. Besar kecil dimensi disesuaikan berdasarkan standar ukuran tubuh manusia dengan memperhatikan kapasitas yang dibutuhkan dalam satu ruangan tersebut, agar desain akhir pada sebuah ruang akan proposional dan ergonomic.

Kenyamanan dapat didukung melalui jarak singgung antar manusia, dimana manusia memiliki area privasi yang di respon oleh tubuhnya [6]. Kenyamanan terbentuk karena adanya variabel-variabel yang 
mendukung terciptanya kenyamananan tersebut. Variabel tersebut dapat berupa dimensi yang mendukung kenyamanan berdasarkan perbandingan skala manusia dengan batasan-batasan maupun luasan ruang di sekitarnya. Meskipun dimensi yang ada tidak bisa dijadikan tolak ukur sebuah kenyamanan namun setidaknya dimensi tersebut harus bisa memenuhi standar dalam penggunaannya. Kenyamanan tidak dapat di tentukan secara personal maupun general, karena definisi kenyamanan bisa berbeda berdasarkan perasaan masing-masing individu. Atas dasar berbagai kebutuhan, berbagai jenis manusia untuk bergerak, maka dapat diperhitungkan dimensi jalur sirkulasi minimum agar semua golongan pengguna dapat bergerak dengan baik.

Ruang gerak merupakan batasan -batasan manusia bebas dalam bergerak. Pertimbangan faktor manusia dari ukuran dan dimensi tubuh, di samping beberapa wawasan aspek fisiologis dan antropometri teori ini berisikan informasi mengenai:

- Besaran Ruang yang dibutuhkan manusia untuk bergerak

- Tingkat privasi manusia dalam itungan radius

- Ukuran tubuh manusia

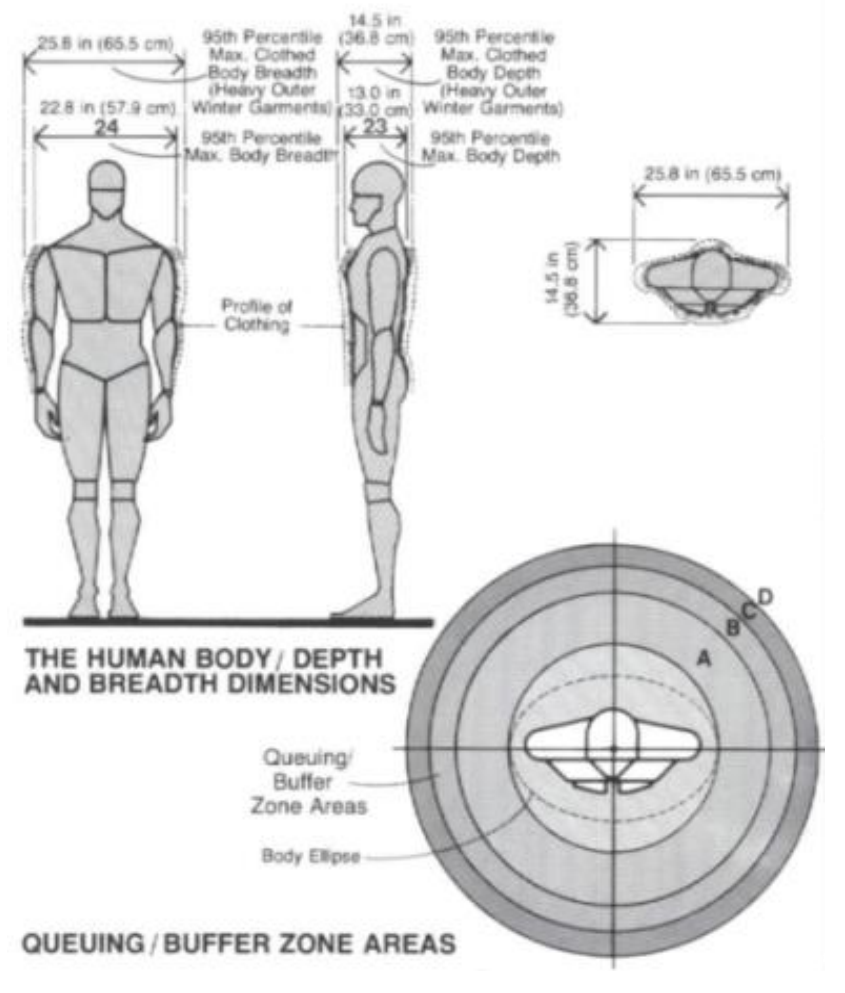

Gambar 2. Ruang gerak \& tingkat zona

Sumber: Ching, Francis D.K. 2009. Bentuk, Ruang, dan Tatanan [5]

\subsection{Kenyamanan Pencapaian}

Menurut Satwiko (2009) kenyamanan dan perasaan nyaman adalah penilaian komprehensif seseorang terhadap lingkungannya. Manusia menilai kondisi lingkungan berdasarkan rangsangan yang masuk kedalam dirinya melalui ke enam indera syaraf dan dicerna oleh otak untuk dinilai.Dalam hal ini yang terlibat tidak hanya masalah fisik biologis, namun juga perasaan. Suara, cahaya, bau, suhu dan lain-lain rangsangan ditangkap sekaligus, lalu dicerna oleh otak. Kemudian otak akan memberikan penilaian relatif apakah kondisi itu nyaman atau tidak. Ketidak nyamanan di satu factor akan ditutupi oleh factor lain. 
Kenyamanan dapat ditentukan oleh beberapa unsur pembentuk dalam perancangan yakni diantaranya sirkulasi, daya alam/iklim, kebisingan, aroma/bau-bauan, bentuk, keamanan, kebersihan, keindahan dan penerangan. Dilihat dari pernyataan tersebut dapat kita ketahui bahwa kenyamanan dapat ditinjau dari segi sirkulasi yang tercipta. Kenyamanan dapat berkurang karena sirkulasi yang kurang baik, seperti tidak adanya pembagian ruang yang jelas atau tidak ada pembagian sirkulasi antara ruang satu dengan ruang lainnya. Sirkulasi dibedakan menjadi dua yaitu sirkulasi di dalam ruang dan sirkulasi di luar ruang atau peralihan antara dalam dan luar seperti foyer atau lobi, koridor, atau hall.

Menurut Uterman (1984) jarak nyaman orang berjalan sekitar \pm 400 meter dan \pm 300 meter apabila membawa barang. Jarak berjalan di atas 400 meter sudah mulai teras tidak nyaman, orang cenderung memilih alternatif lain [4].

\section{METODOLOGI}

Metode yang digunakan dalam penelitian ini berupa analisis deskriptif yang ditinjau berdasarkan teori melalui substansi yang menjadi variabel dalam mengevaluasi sebuah kenyamanan pada pencapaian di Rumah Sakit Dustira Cimahi. Tahap- tahapan dari penelitian desain sirkulasi ini tentunya berawal dari penelusuran masalah yang ditinjau dari permasalahan desain sirkulasi pada kawasan rumah sakit dengan konsep bangunan multi massa. Permasalahan ini ditinjau dari aspek masalah kenyamanan pencapaian yang sering dirasakan pasien ataupun pengunjung ketika berkunjung ke rumah sakit. Hal ini menjadi dasar pemikiran bagi penulis untuk meninjau data kongkrit di lapangan baik berupa pengalaman ataupun data tercetak berupa gambar. Kemudian data ini diolah menjadi sebuah bahan pembahasan untuk di bandingkan dengan teori sirkulasi, teori zoning ruang, dan teori kenyamanan pencapaian. Setelah mencapai titik temu pada sebuah bahasan penelitian, maka keluarlah kesimpulan bahwa desain sirkulasi pada kawasan Rumah Sakit Dustira telah memenuhi standar.

\section{HASIL DAN PEMBAHASAN}

\subsection{Klasifikasi Rumah Sakit Dustira}

Jumlah tempat tidur yang tersedia di Rumah Sakit Dusitra sebanyak 496 unit yang terbagi atas 479 regular dan 17 VIP dengan pelayanan medis 15 spesialistik dan 4 sub spesialistik. Sesuai dengan peraturan menteri kesehatan bahwa jumlah tempat tidur rumah sakit kelas A sebanyak 400 unit, kelas B berjumlah 200 unit tempat tidur, kelas $\mathrm{C}$ berjumlah 100 unit tempat tidur dan kelas D berjumlah 50 unit tampat tidur [1]. Berdasarkan jumlah tempat tidur dan pelayanan medis rumah sakit Dustira dapat dikategorikan sebagai rumah sakit kelas A, namun perlengkapan alat-alat medis sebagai fasilitas pelayanan spesialistik yang tersedia Rumah Sakit Dustira masih belum memenuhi persyaratan dan kriteria yang cukup untuk rumah sakit kelas A, sehingga masih digolongkan pada klasifikasi rumah sakit kelas B.

Tabel 3. Fasilitas dan layanan Rumah Sakit Dustira

\begin{tabular}{cccc}
\hline \multicolumn{2}{c}{ Jumlah Tempat Tidur } & \multicolumn{2}{c}{ Pelayanan Medis } \\
\hline Regular & VIP & Spesialistik & Sub Spesialistik \\
\hline 479 & 17 & 15 & 4 \\
\hline
\end{tabular}

\subsection{Analisis Zoning}

Zoning pada kawasan Rumah Sakit Dustira terbagi berdasarkan zona OPD, IPD, IGD (Instalasi Gawat Darurat) atau Accident \& Emergency, Operating Departmen, administrasi dan service yang terintegrasi sesuai dengan fungsi masanya jika dilihat berdasarkan teori Isadore mengenai zoning rumah sakit [3]. Beberapa fungsi tersebar diberbagai area, seperti bangunan administrasi yang sebagian massanya berada dekat jalan masuk (entrance) dari jalan Dustira, dan sebagian lagi dekat dengan akses masuk servis 
yang berada di jalan Sudirman. Selain itu posisi ruang perawatan sebagai pusat dari kawasan rumah sakit terorganisir dengan jelas meski massa bangunannya cukup tersebar di berbagai area tetapi tidak mengurangi konektifitas antar masa yang terhubung koridor dengan baik, seperti terlihat pada Gambar 3.

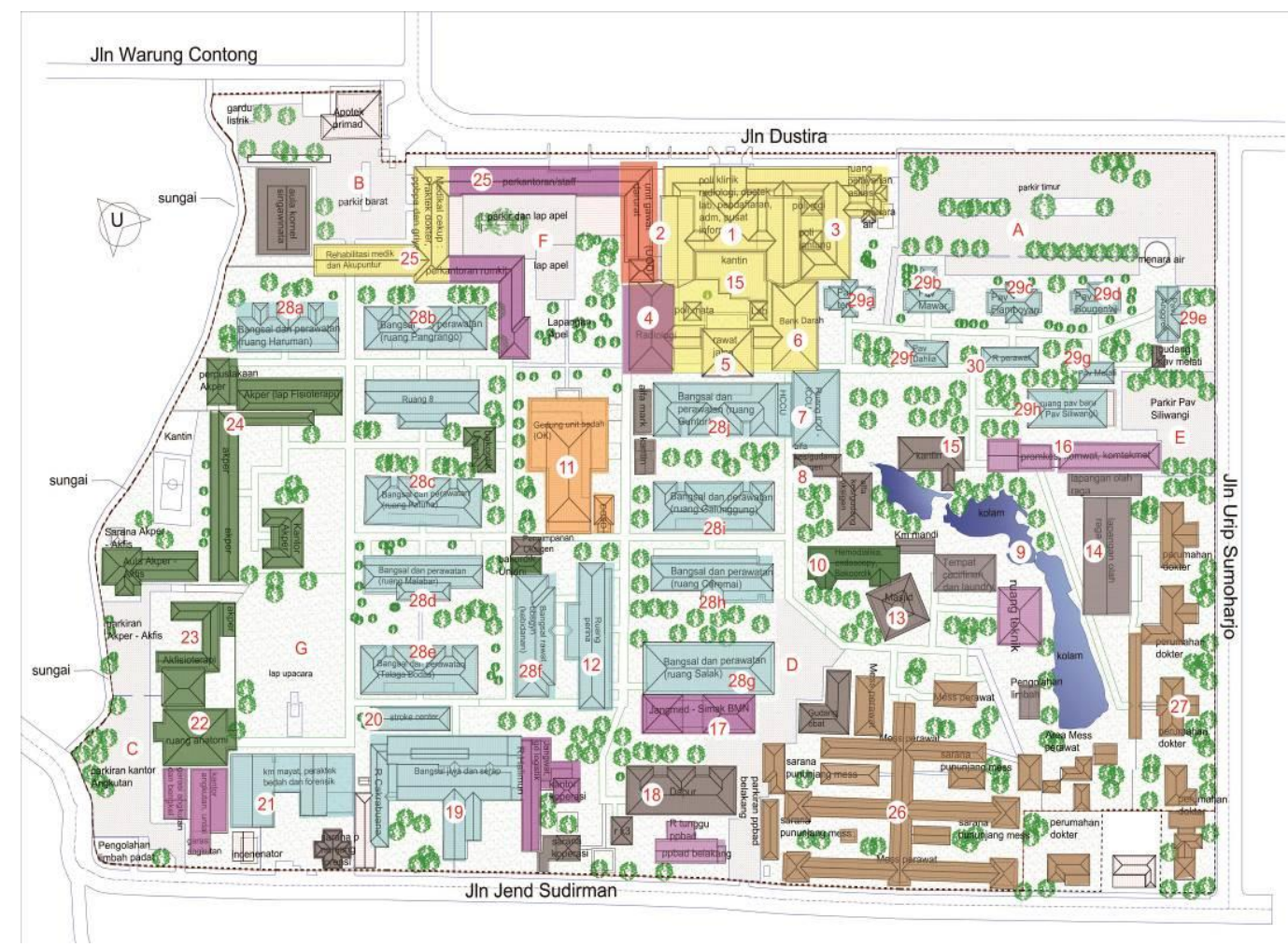

\begin{tabular}{|l|r|r|}
\hline REKAPITULASI LAHAN RUMAH SAKIT DUSTIRA & & \\
\hline LUAS LAHAN TERBANGUNAN RUMAH SAKIT DUSTIRA & $72,876.88 \mathrm{~m} 2$ & $53.88 \%$ \\
\hline LUAS LAHAN HIJAU RUMAH SAKIT DUSTIRA & $62,373.17 \mathrm{~m} 2$ & $46.12 \%$ \\
\hline LUAS TOTAL LAHAN & $135,250.05 \mathrm{~m} 2$ & $100.00 \%$ \\
\hline
\end{tabular}

Keterangan:

$\begin{array}{lll}\text { OPD (Out-patient Departement) } & \text { IPD (In-patient Departement) } & \text { Operating Departement } \\ \text { a. Poli Anak } & \text { a. ICU (Intensive Care Unit) } & \text { Ruang Sterilisai } \\ \text { b. Poli Penyakit dalam } & \text { b. HCU (High Care Unit) } & \text { b. Radiology } \\ \text { c. Poli Bedah } & \text { c. NICU (Neonatal Intensive Care } & \text { Administration } \\ \text { d. Poli Obstetric \& Gynaecology } & \text { dnit) } & \text { a. Front Office } \\ \text { e. Poli Penyakit Jantung } & \text { d. PICU (Pediatrical Intensive Care } & \text { b. Back Office } \\ \text { f. Poli Penyakit Gigi } & \text { e. Rnit) } & \\ \text { g. Poli Penyakit Mata } & \text { f. Ruang Rawat VIP } & \text { Servis } \\ \text { h. Poli Jiwa } & \text { g. Ruang Rawat Kelas 1B } & \text { a. Dapur } \\ \text { i. Poli Penyakit Syaraf } & \text { h. Ruang Rawat Kelas 2B } & \text { b. Gudang Oksigen } \\ \text { j. Poli Penyakit THT } & \text { i. Ruang Rawat Kelas 3B } & \text { c. Gudang Obat } \\ \text { k. Poli Gizi } & \text { d. Kantin } \\ \text { l. Poli Kulit dan Kelamin } & \text { Accident \& Emergency } & \text { e. Laundry } \\ \text { m. Poli Fisioterapi } & \text { a. Instalasi Gawat Darurat } & \text { f. Bengkel Ambulan } \\ \text { n. Poli Akupuntur } & \text { b. Ambulan } & \end{array}$

Gambar 3. Zoning rumah sakit

Sumber: Dokumen Rumah Sakit Dustira (diedit 23 November 2018) 


\subsection{Analisis Sirkulasi pada Bangunan Multi Massa}

Penerapan Sistem sirkulasi pada kawasan terbagi menjadi tiga pola, diantaranya terdapat sirkulasi dengan pola grid di area perawatan yang massanya cukup banyak. Hal ini bertujuan agar massa bangunanan tertata dengan rapih dan dapat mempermudah pasien atau pengunjung untuk menemukan massa ruang perawatan yang dituju. Pola linear diterapkan di bagian ruang perawatan pavilion yang masanya tidak terlalu banyak sehingga bangunan tertata dalam dua baris dan dapat ditempuh melalui satu koridor panjang yang melewati seluruh massa perawatan pavilion. Sirkulasi dengan pola radial yang diterapkan di area OPD sebagai area medical central unit dan ruang tunggu sebagai pusat kegiatan, hal ini agar pasien atau pengunjung dapat dengan jelas melihat mana ruang yang harus dituju karena setiap ruang berada di sekitar area tunggu. Dalam sebuah bentuk sirkulasi terdapat tingkat persentasi penggunaan dilihat berdasarkan sifat sirkulasi. Ketiga pola tersebut terbentuk melalui 3 sifat sirkulasi yang tersusun secara berbeda diantaranya sirkulasi primer, skunder, dan tersier [5] dapat dilihat pada Gambar 4.

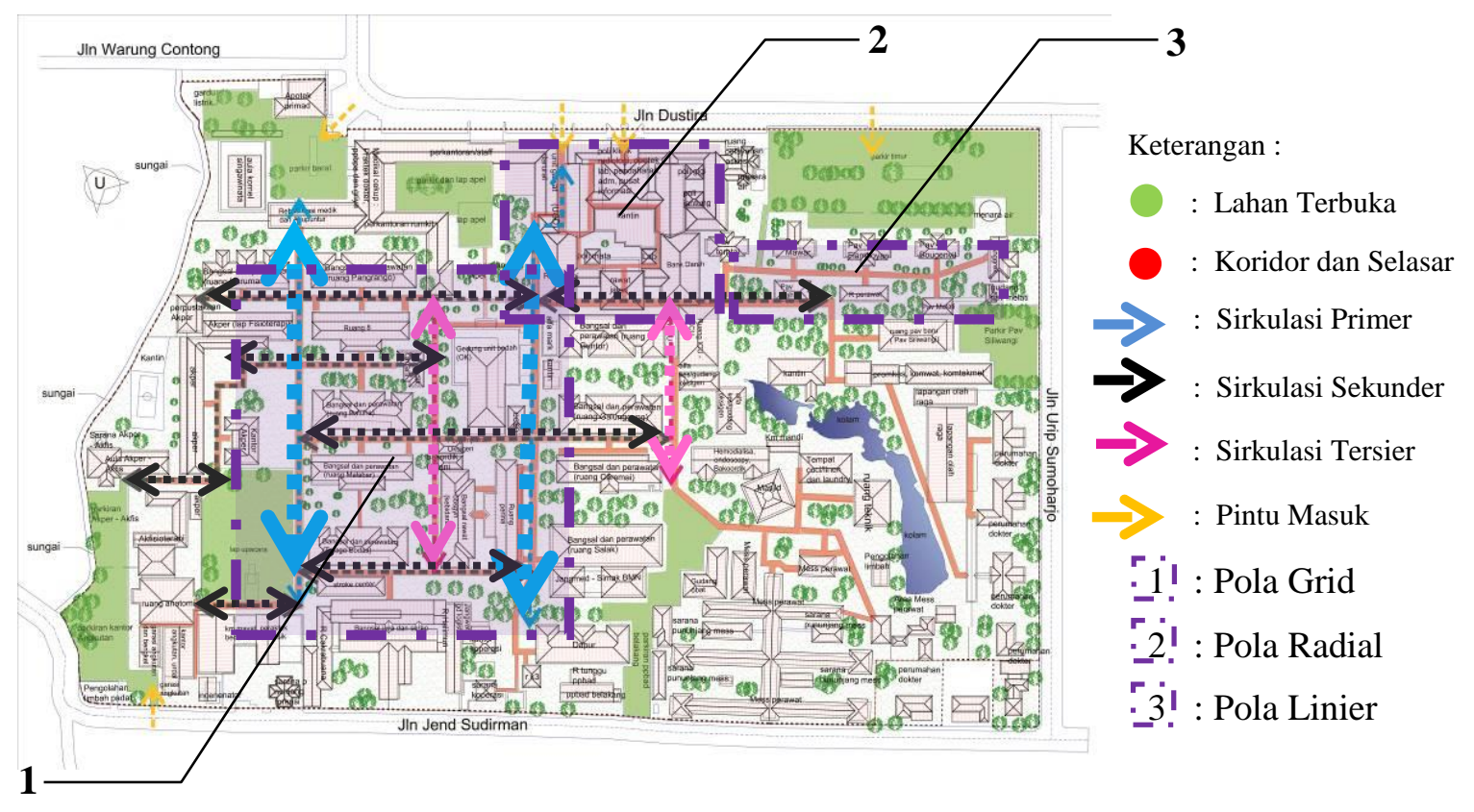

Gambar 4. Sifat sirkulasi pada Rumah Sakit Dustira

Sumber: Dokumen Rumah Sakit Dustira (diedit 23 November 2018)

Sifat-sifat sirkulasi dapat dilihat berdasarkan seberapa seringnya pasien atau pengguna menggunakan jalur tersebut. Sirkulasi primer merupakan sirkulasi utama berupa koridor yang langsung terhubung dengan pintu masuk utama (main entrance) atau dapat diartikan sebagai sebuah koridor pertama yang dilalui oleh pengunjung untuk mencapai massa bangunan rumah sakit. Koridor utama tersebut dihubungkan kembali melalui sirkulasi sekunder yang merupakan jalur koridor kedua yang di lalui pengunjung untuk menuju pintu masuk setiap massa bangunan pada kawasan rumah sakit. Sirkulasi tersier merupakan penghubung antar massa pada kawasan yang sifatanya tidak terhubung dengan jalur koridor utama atau sirkulasi primer, dapat dilihat pada Gambar 4.

\subsection{Analisa Kenyamanan Pencapaian}

Kenyamanan desain sirkulasi tidak dapat dilihat dari satu sudut pandang melainkan dapat dipengaruhi oleh berbagai aspek sirkulasi. Kenyamanan pada kawasan Rumah Sakit Dustira dipengaruhi beberapa unsur kenyamanan [5].

\subsubsection{Pintu Masuk}

Rumah Sakit Dustira memiliki 11 akses pintu masuk, yang terbagi atas 5 pintu masuk dari di Jalan Dustira, 4 diantaranya untuk publik dan 1 untuk staff. Pada Jalan Urip Sumoharjo terdapat 2 pintu masuk untuk publik sedangkan pada jalan Sudirman terdapat 4 pintu masuk yaitu 2 pintu masuk untuk staff 
dan servis, serta 2 akses pintu masuk umum dan pendidikan seperti pada gambar 5. Pintu masuk sebagai entrance untuk masuk kedalam kawasan yang luas, multi masa dan dikelilingi oleh 3 jalan arteri primer dan sekunder merupakan akses yang tidak cukup efektif bagi pengguna yang belum pernah ke lokasi tersebut.

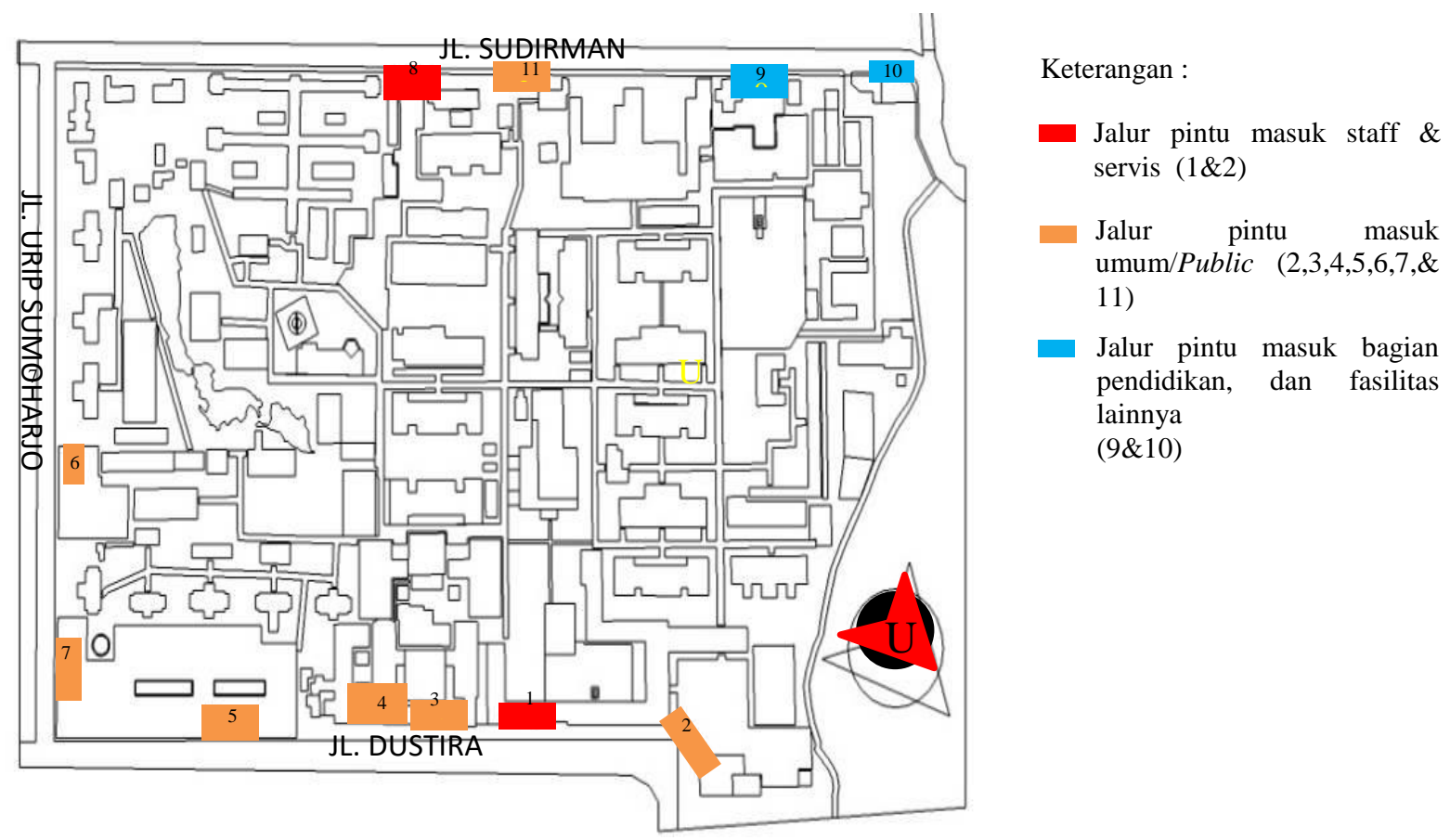

Gambar 5. Akses pintu masuk Rumah Sakit Dustira

\subsubsection{Sirkulasi Pencapaian}

Pada rumah sakit Dustira terdapat 2 tipe sirkulasi pencapaian yakni menembus ruang dan melewati antar masa yang menggunakan koridor. Tipe sirkulasi menembus ruang berada dibagian ruang rawat jalan (OPD) yang bertujuan agar pengguna dapat mengakses ruang lain yang akan dituju dengan cara memotong jalur agar jarak tempuh lebih pendek dan waktu tempuh menjadi lebih singkat, sedangkan jika melewati jalur sirkulasi antar fungsi masa melalui sarana sirkulasi koridor (selasar penghubung antar masa) maka jarak tempuh menjadi lebih panjang dan waktu tempuh menjadi lebih lama, seperti terlihat pada Gambar 6.

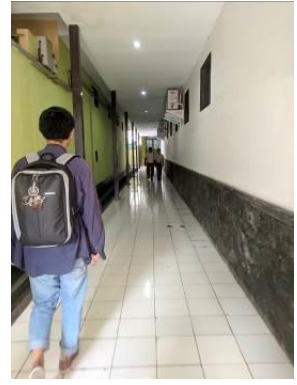

Menembus Ruang, koridor antar ruang

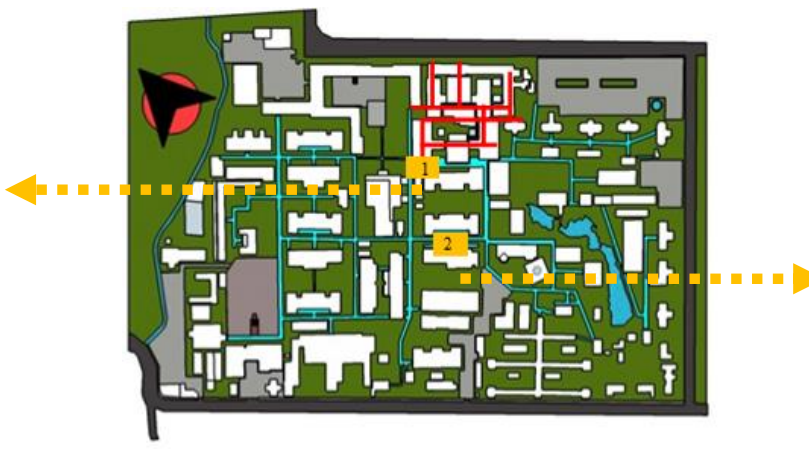

Gambar 6. Sirkulasi pencapaian Rumah Sakit Dustira

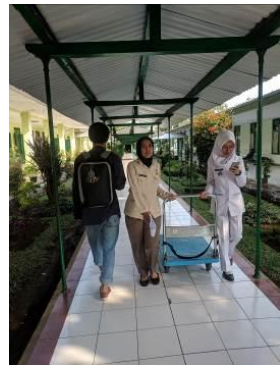

Melewati Fungsi Ruang, Selasar penghubung masa 


\subsubsection{Signage}

Signage pada Rumah Sakit Dustira terpasang disetiap persimpangan koridor dan bagian depan bangunan sebagai petunjuk dan informasi umum bagi pengguna rumah sakit. Signage yang digunakan berupa papan yang terbuat dari besi yang di cat dan berisikan informasi yang menunjukan nama ruang dan simbol seperti arah panah. Fungsi utama signage adalah untuk menunjukan posisi atau orientasi ruang dan massa bangunan yang akan dituju oleh pengguna, agar memudahkan pasien dan pengunjung dalam menentukan posisi yang dicari . Beberapa contoh dan lokasi signage dapat dilihat pada Gambar 7.

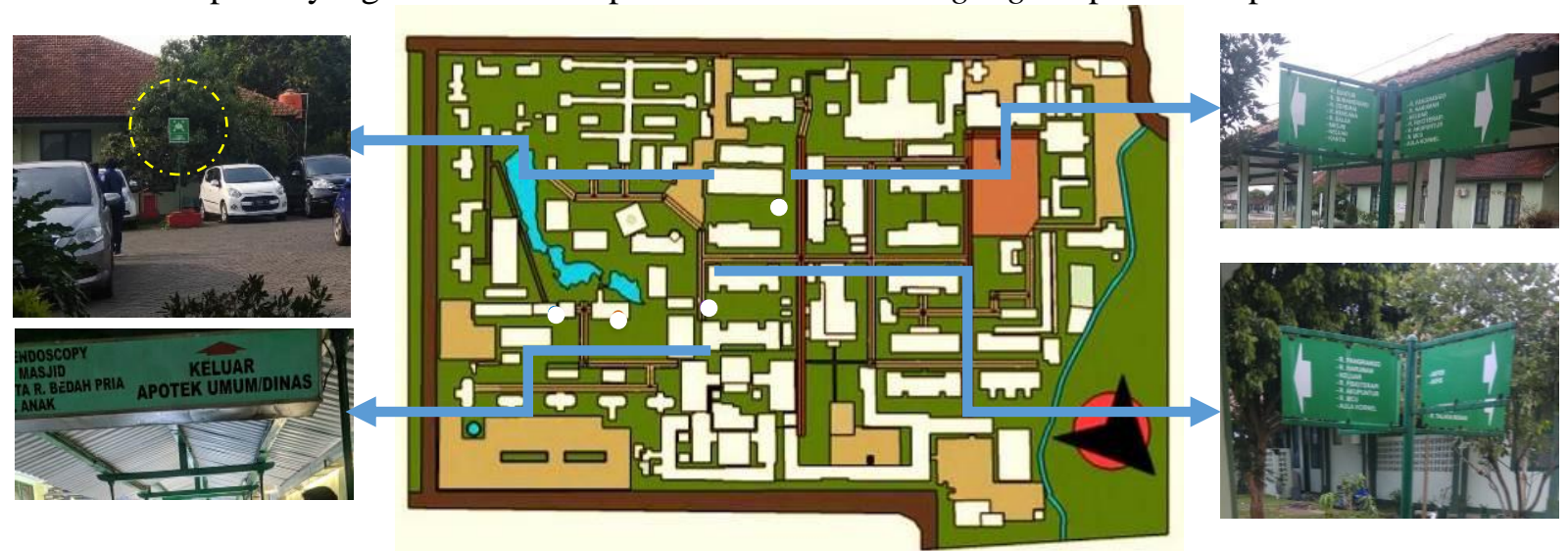

Gambar 7. Signage Rumah Sakit Dustira

\subsubsection{Jarak}

Jarak dapat diartikan sebagai ukuran pencapaian pada perbedaan posisi dari kedua bangunan atau bahkan lebih. Perbedaan jarak dapat dirancang sedemikian rupa berdasarkan kebutuhan fungsional, kondisi fisik lingkungan, dan ditinjau dari objek apa yang akan dirancang. Pada rumah sakit pengguna cenderung mengharapkan pencapaian dengan tujuan langsung, karena pasien atau pengunjung mengharapkan bahwa perjalanan dalam sistem sirkulasi ini akan lebih singkat dan cepat dengan jarak seminimal mungkin [4]. Semakin dekat jarak antar massa maka semakin cepat pula pasien atau pengunjung mencapai bangunan lainnya. Pemetaan area juga sangat penting bagi fungsi kawasan yang memiliki banyak massa di dalamnya. Pada kawasan rumah sakit massa terbagi di beberapa area yang mengakibatkan jarak antar massa berbeda, dapat dilihat pada Gambar 8.

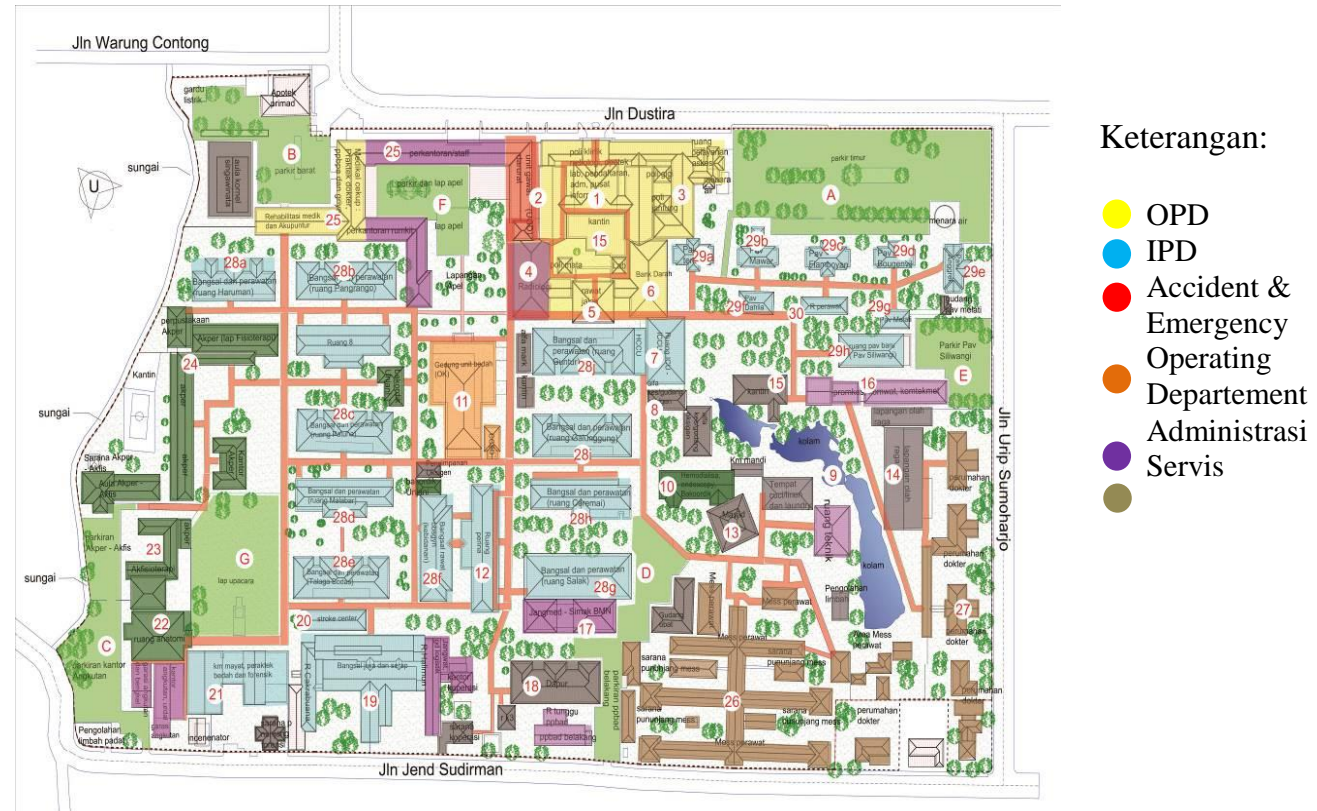

Gambar 8. Zoning dan konektivitas ruang

Sumber: Dokumen Rumah Sakit Dustira (diedit 23 November 2018) 
Kenyamanan Pencapaian Pengguna Bangunan Rumah Sakit Multi Massa terhadap Desain Sirkulasi sebagai Penghubung Antarfungsi Bangunan

Tabel 4. Jarak pencapaian antarzona

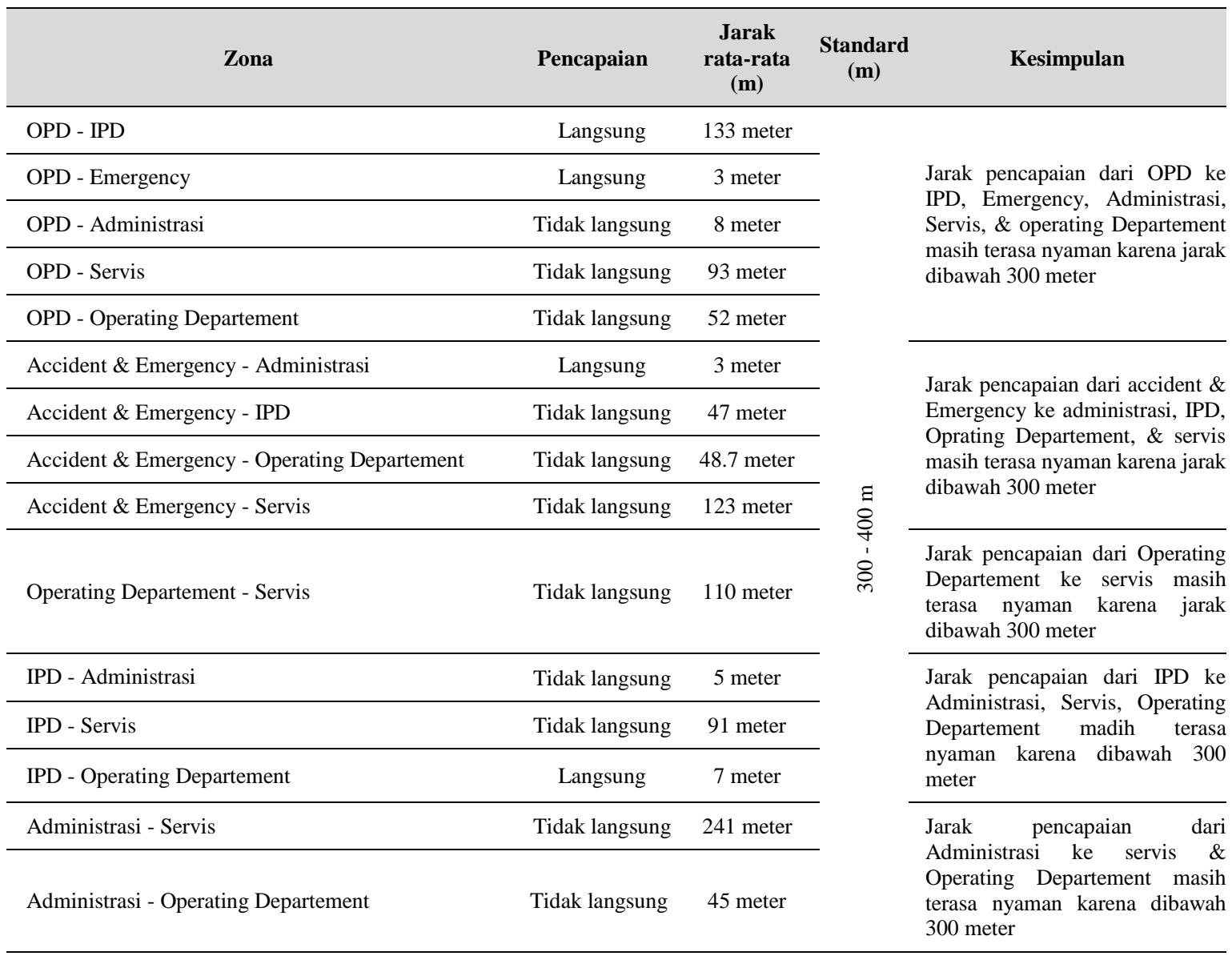

\subsubsection{Material}

Penggunaan material pada koridor menggunakan keramik berukuran $30 \mathrm{~cm}$ x $30 \mathrm{~cm}$ dengan warna yang cerah, penggunaan material karet dan perbedaan warna pada ramp koridor mempermudah pengguna untuk membedakan elevasi kemiringan lantai dan bertujuan agar pijakan kaki tidak licin sehingga dapat mengakses koridor dengan aman dan nyaman. Penghubung koridor dengan teras setiap massa menggunakan material tegel berfungsi sebagai ramp agar tidak licin, karena elevasi lantai koridor dan teras bangunan tidak sama sehingga dapat mempermudah pengguna untuk mengakses koridor. Penggunaan paving blok di area terbuka dapat meningkatkan daya serap air ke tanah dan tekstur yang kasar pada paving blok dapat menahan gesekan kaki ketika alas kaki terkena lumpur sehingga pengguna merasa aman. Jenis material dapat dilihat pada Tabel 4.

Tabel 5. Material pada sarana transportasi

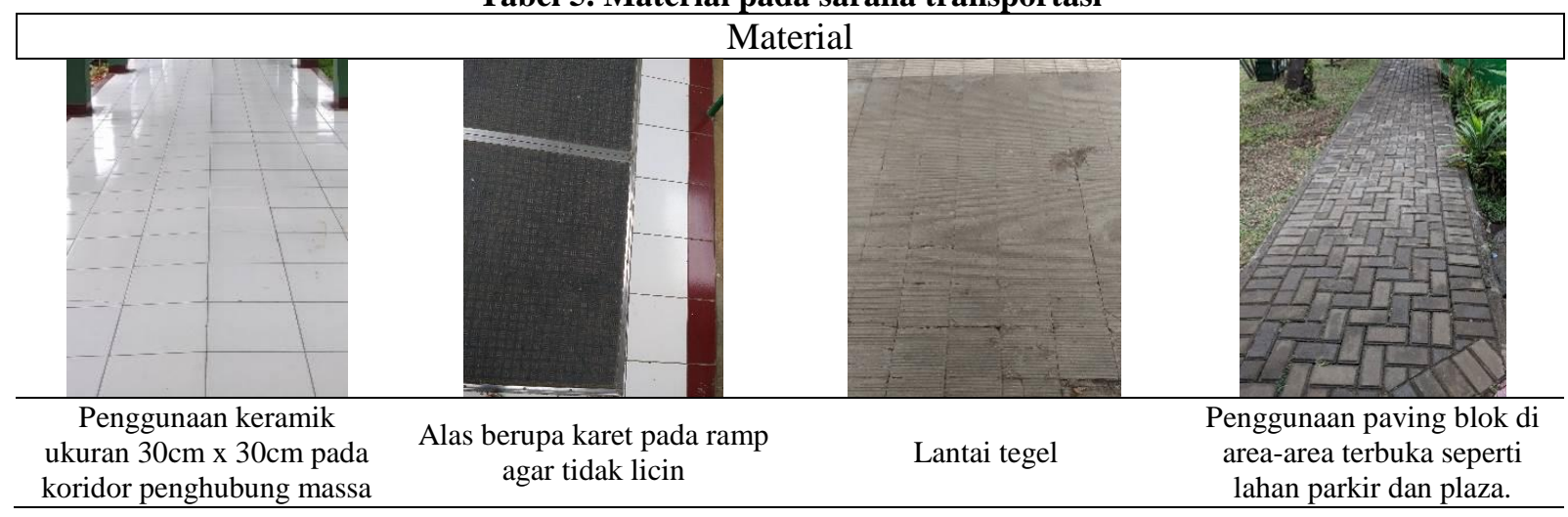




\section{SIMPULAN DAN SARAN}

Berdasarkan analisa penelitian dengan judul "Desain Sirkulasi Bangunan Multi Massa Terhadap Kenyamanan Pencapaian Pengguna pada Rumah Sakit Dustira Cimahi”, dapat diambil kesimpulan antara lain:

1. Klasifikasi Rumah Sakit Dustira

Rumah Sakit Dustira merupakan Rumah Sakit kelas B, karena masih kurangnya fasilitas peralatan medis dan kemampuan pelayanan pada Rumah Sakit tersebut.

2. Zoning / Tatanan Massa \& Pola Sirkulasi

Zoning pada kawasan terkelompok dengan baik. Penempatan zona pada Rumah Sakit Dustira tidak mengurangi hierarki pada tiap fungsi masssanya, dan tetap terintegrasi dengan sangat optimal. Sirkulasi menjadi sangat efektif dan sangat membantu pengguna dalam berorientasi pada kawasan rumah sakit yang memiliki bangunan multi massa. Kawasan Rumah Sakit Dustira menerapkan tiga sistem pola sirkulasi berdasarkan tatanan multi massa yang terbentuk, diantaranya berupa pola grid di area perawatan. Penerapan pola radial di area OPD (Out-patient Departement) sebagai area Medical Central Unit. Sirkulasi dengan pola linier diterapkan di area pavilion. Ketiga pola sirkulasi ini dapat mengakomodasi kebutuhan pada setiap zona yang terbagi atas beberapa masa (multi masa) dengan baik dan efektif.

3. Kenyamanan Pencapaian Pengguna

Unsur-unsur kenyamanan yang terdapat pada kawasan Rumah Sakit Dustira untuk memenuhi kriteria standar kenyamanan dalam bersirkulasi antara lain; Pintu masuk sebagai entrance untuk masuk kedalam kawasan yang luas, cukup banyak akses dan kurang efektif. Dengan adanya penghubung ruang dan masa berupa selasar dan koridor sangat membantu pengguna dalam melaksanakan kegiatan pada tatanan masa yang cukup banyak. Selain itu juga ditunjang adanya panjang koridor yang tidak melebihi jarak maksimal 400 meter orang masih merasakan nyaman dengan tekstur dan warna material yang mendukung. Sebagai pelengkap kenyamanan pencapaian pada kawasan multi masa adanya signage sebagai penunjuk arah tujuan dan pengguna berorientasi.

\section{UCAPAN TERIMAKASIH}

Jurnal ini tidak dapat terselesaikan tanpa bantuan dari beberapa pihak yang terlibat, baik secara langsung maupun tidak langsung. Oleh karena itu, pada kesempatan kali ini penulis bermaksud untuk menyampaikan rasa terima kasih yang sebesar-besarnya kepada seluruh Direktur/Kepala Bagian dan seluruh staf Rumah Sakit Dustira Cimahi yang telah mendukung serta membantu dalam memberikan data maupun informasi yang dibutuhkan selama proses penelitian.

\section{DAFTAR PUSTAKA}

[1] Peraturan Mentri Kesehatan No 34 tahun 2016

[2] De Chiara, Jhose P. (1997). Standar Perencanaan Tapak. Jakarta: Erlangga

[3] Rosenfield, Isadore. (1956). Hospitals Integreted Design. U.S.A; Reinhold Publishing Corporation

[4] Hakim, Rustam. (1987). Unsur Perancangan dalam Arsitektur Lansekap

[5] Ching, Francis D.K. (2009). Bentuk, Ruang, dan Tatanan. Jakarta: Erlangga

[6] Panero, Julius \& Martin Zelnik. (1979). Human Dimension and Interior Space. U.S.A; Whitney Library of Design 